\title{
Orthodontic traction technique: Clinical case report based on literature
}

\author{
Isabella Sabino Maceno ${ }^{1}$, Samara Christina dos Santos ${ }^{1}$, Leandro Moreira Tempest ${ }^{1,2}$, Idiberto José Zotarelli Filho ${ }^{2 *}$ and Carlos Alberto \\ Costa Neves Buchala ${ }^{1,2}$ \\ ${ }^{1}$ University Center North Paulista (Unorp) - São José do Rio Preto - SP, Brazil \\ ${ }^{2}$ Post graduate and continuing education (Unipos), Street Ipiranga, 3460, São José do Rio Preto SP, Brazil
}

\begin{abstract}
The canines are extremely relevant elements in the dental arch, justifying the great aesthetic and functional importance. However, its eruption pathway is long and complex, one of the causes described in the literature to justify ectopic eruption and impaction of permanent superior canines, especially in the palatal region. The impaction of the upper canines is defined when the tooth does not erupt after six months of the root being completely formed. This impaction can lead to several pathologies in untreated patients. That is why the ideal age to diagnose is between 10 and 12 years. The excellence of the treatment translates into the correction of occlusion, smile harmony, periodontal health and post-treatment stability. . Surgical techniques along with orthodontic treatment are widely used for correct positioning in the arcade. Thus, this work aims to show, through a literature review and clinical case report, orthodontic-surgical techniques for traction of impacted and or included canines.
\end{abstract}

\section{Introduction}

After the third molars, permanent maxillary canines have the highest incidence of impaction, representing $2.0 \%$ of the population [1-5]. The canine impaction is twice as large in females and can be uni or bilateral. Approximately 80.0 to $90.0 \%$ of impacted canines are on the palate and $20.0 \%$ per vestibular [6-8]. The dental movements during the eruption are complex and are followed minute by coordination of tooth growth, alveolar process growth and bone growth. Any disturbance in this correlation may affect the direction of movement [5].

The integration of surgery with orthodontics is essential for cases in which the trauma occurred in the deciduous tooth caused disturbance and eruption in the permanent successor. Among these disorders, the occurrence of impaction of the element is common, causing great harm to the patient. In addition to aesthetic issues, the absence of anterior teeth, for example, implies a functional defect in the protrusive movement, reflecting negatively on the temporo-mandibular joint $[2,3]$.

Therefore, in view of the different treatment methods, it was motivated to perform a literature review in order to elucidate the various aspects related to orthodontic traction of the upper canines and, especially, to highlight an effective way of performing this procedure.

\section{Literature review}

The review of the literature will be based on a historical perspective of the studies and articles concerning the subject from the etiological factors to the protocols of treatment of retained upper canines, in resonance with the present case report, according to the figures 1,2 and 3 .

\section{Etiology of impaction}

According to Moyers, et al. [1] causes can be primary and secondary. He enumerated as primary causes: 1 ) Root resorption of the deciduous tooth; 2) Trauma of germs of deciduous teeth; 3) Availability of arc space; 4) rotation of permanent tooth germs; 5) Premature closure of the root tips; 6) eruption of canines in areas of cleft palate. As secondary causes: 1) Abnormal muscle pressure; 2) Febrile diseases; 3) Endocrine disorders; and 4) Vitamin D deficiency.

The high incidence of canine palatino impaction may be associated with decreased size and ectopic position of the lateral incisor. The explanation for palatal impaction, too, may be associated with excessive space in the canine area that will allow the tooth to move gradually in the bone and find a location behind the other teeth. This space can be created by: 1) excessive bone growth in the canine area, 2) agenesis or hypo development of the lateral incisor, and 3) stimulated eruption of the lateral incisor or first premolar [5].

\section{Diagnosis}

The diagnosis of impaction after anamnesis is performed by means of clinical and radiographic examinations. According to Bishara, et al. [3], the main signs to be observed in the clinical examination are: delay of eruption after the age of 14 years, prolonged retention of primary canines, elevation of the labial or palatal mucosa, distal migration of the upper lateral incisor, with or without deviation of the medium line. Radiographic examination is essential in the radiographic elaboration, as it proves the canine impaction and its location in the vestibular-

Correspondence to: Idiberto José Zotarelli Filho, Unipos - Post graduate and continuing education, Street Ipiranga, 3460, São José do Rio Preto SP, Brazil , 15020-040, Tel: +55(17) 98166-6537 / +55(17) 98803-7459; E-mail: m.zotarelli@ gmail.com

Key words: orthodontic surgery, traction technique, traction of canine teeth

Received: February 02, 2018; Accepted: February 23, 2018; Published: February 27,2018 


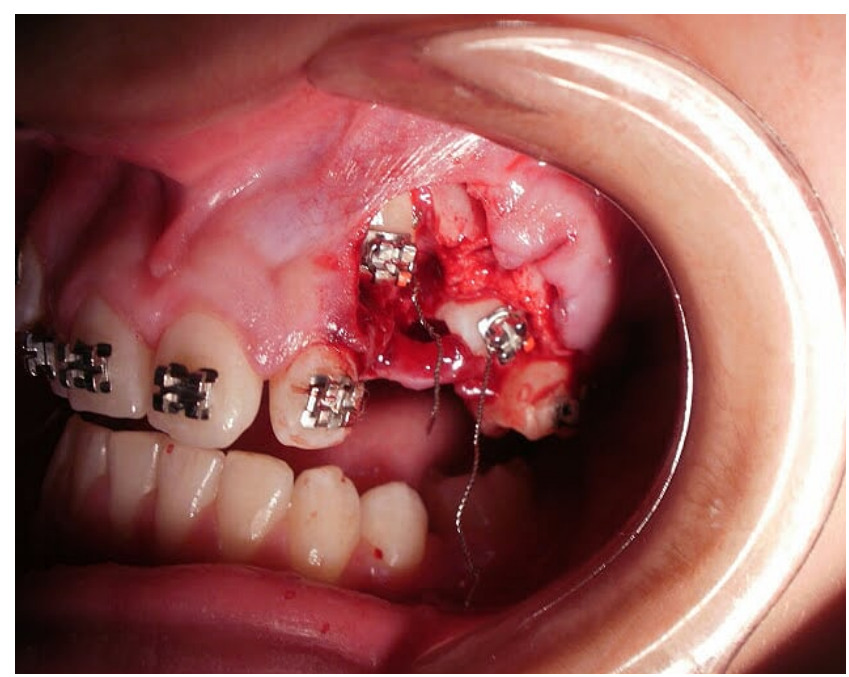

Figure 1. Orthodontic-surgical technique for traction of impacted and included canines

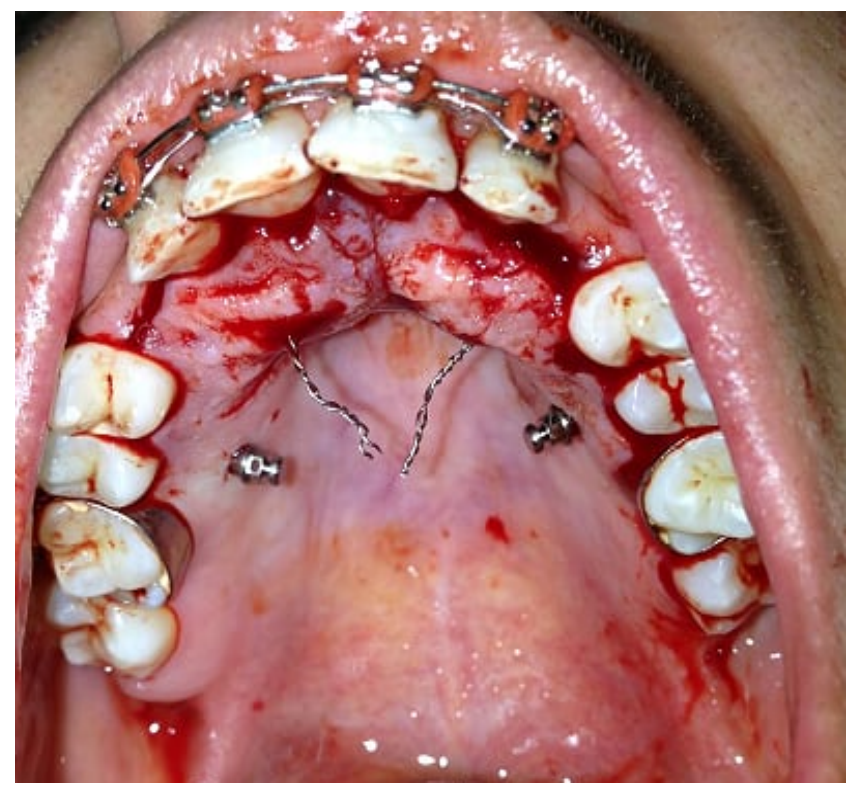

Figure 2. Orthodontic-surgical technique

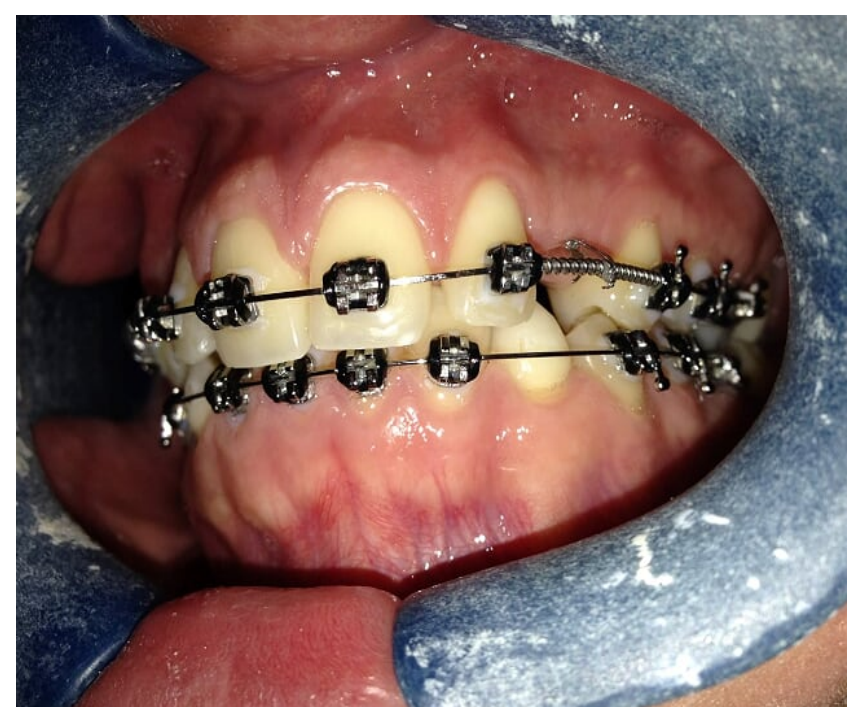

Figure 3. Image after orthodontic-surgical technique lingual, cervico-occlusal and mesio-distal directions, as well as its relation with adjacent structures $[7,8]$.

The simplest but reliable means for initial diagnosis is periapical radiography. The Clarck technique should be used to evaluate the vestibular-palatine position of the impacted tooth. Another method of imaging is to use a CT scan. This method allows safer and more accurate planning with respect to orthodontic movement. It has higher image quality than conventional radiographs, however, it still has a high cost and its dose of radiation, relatively high, limits the indications for its use [8]

Tanaka, et al. [9] concluded that, once diagnosed the impaction, one should choose: 1) Nothing to do if the patient so wishes; 2) Selftransplantation; 3) Exodontia of the canine and movement of the premolars to the position of this; 4) Restoration of the occlusion by means of a prosthesis; and 5) Surgical exposure and orthodontic treatment to move the tooth to the occlusion line. The latter option has been shown to be efficient, especially when well diagnosed and performed using the appropriate technique.

\section{Treatment protocols}

Because of the importance of upper canine functions and their permanence in the arch, the orthodontist should consider the various treatment options available. They are: 1) No treatment: Wait for the spontaneous eruption of the canine retained, removing mechanical interferences as well as abnormalities, pathologies and even recovery of space.

In this case it is necessary to have a radiographic control; 2) Autogenous transplantation: Extraction of the canine retained and immediately transplanted to an artificial alveolus performed on the alveolar ridge. In this maneuver pulp necrosis and root resorption are common [5]; 3) Extraction of the deciduous canine: to guide the eruption of the permanent canine; 4) Extraction of impacted canine in the following cases: external and internal root resorption, dilaceration, severe impaction, when the first premolar occupies the place of the canine with an acceptable functional occlusion or when there are pathological alterations [3]; 5) Surgical exposure and orthodontic traction.

\section{Orthodontic traction technique}

The canine traction can be done in several ways: by gluing the traction accessories with the use of the steel wire to lace the tooth; Surgical ring cementation; Threaded pin and piercing of the dental element [9]. The lacing technique is the least indicated because it requires a very extensive and traumatic bone removal, which may result in ankylosis and / or external resorption of the tooth, causing gingival recession and less control of the traction direction [6]. The perforation of the element has as a disadvantage destruction of part of the tissues of the dental crown and the possibility of causing damages to the dental tissues more internal, like the pulp.

The technique of one-button gluing or orthodontic bréquete has become the preferred choice for the traction of impacted teeth. The force applied to the traction must be smooth, at most $60.0 \mathrm{~g} \mathrm{[10].}$

The anchorage with fixed apparatus is used in most cases to move the included teeth. The magnitude of the force for traction should be intermittent, ranging from $24 \mathrm{~g}$ to $60 \mathrm{~g}$. It is also recommended to do anchor reinforcement to minimize any possible side effects. The professional sense should indicate the best procedure for each case, always trying to intervene in the most conservative way possible. Post 
operative control, as well as patient awareness and collaboration are highly relevant aspects for the success or failure of treatment. In cases of failure, alternative approaches should be brought to the attention of patients, parents and caregivers $[8,10]$.

\section{Conclusion}

Among the different therapeutic approaches, tooth traction is the preferential treatment of canines included. The most commonly used fixation method of orthodontic accessories is the direct bonding of the accessory to the enamel of the retained tooth. Fabrics and buttons are the most commonly used devices for gluing. The repositioning flap technique in its original position produces better aesthetic and periodontal results at the end of treatment.

\section{Conflict of interests}

There is no conflict of interest between authors.

\section{References}

1. Almeida RR (1991) Abordagem da Impactação e/ou Irrupção Ectópica dos Caninos Permanentes: Considerações Gerais, Diagnóstico e Terapêutica.
2. Alqerban A (2011) Comparação de dois sistemas de tomografias computadorizadas do tipo cone beam versus a radiografia panorâmica para a localização do canino superior impactado e detecção de reabsorção radicular. Departamento de ortodontia e radiologia da Universidade Católica de Leuven - Bélgic.

3. Bishara SE (1992) Impacted maxillary canines: a review. Am J Orthod Dentofacial Orthop 101: 159-171. [Crossref]

4. Blair GS, Hobson RS, Leggat TG (1998) Posttreatment assessment of surgical exposed and orthodontically aligned impacted maxillary canines. Am J Orthod Dentofacial Orthop 113(3):329-32. [Crossref]

5. Ferreira JTL, Romano FL, Sasso Stuani MB, Assed Carneiro FC, Nakane Matsumoto MA (2017) Traction of impacted canines in a skeletal class III malocclusion: A challenging orthodontic treatment. Am J Orthod Dentofacial Orthop 151: 1159-1168. [Crossref]

6. Garib DG (1999) Caninos superiores retidos: Preceitos clínicos e radiográficos. $R$ Dental Press Ortod Ortop Facial Maringá.

7. Jacobs GS (1999) Localization of the unerupted maxillary canine: How to and when to. American J Orthodontics Dentofacial Orthopedics.

8. Kılıç N, Oktay H (207) Orthodontic intervention to impacted and transposed lower canines. Case Rep Dent 2017: 4105713.

9. Tanaka $\mathrm{O}$ (2003) Consideração para o tracionamento de caninos superiores impactados por vestibular. Ver. ABO Nac.

10. Vellone V, Cirignaco G, Cavarretta B, Cascone P (2017) Canine eruption after secondary alveolar bone graft in unilateral cleft lip and palate patients. J Craniofac Surg.

Copyright: $\odot 2018$ Maceno IS. This is an open-access article distributed under the terms of the Creative Commons Attribution License, which permits unrestricted use, distribution, and reproduction in any medium, provided the original author and source are credited. 